\title{
DIÁLOGOS ENTRE A HISTÓRIA DA EDUCAÇÃO E LITERATURA: A ESCOLA NORMAL NO ROMANCE A NORMALISTA, DE ADOLFO CAMINHA (1893)
}

\author{
Caio Corrêa Derossi ${ }^{1}$ \\ Joana D'Arc Germano Hollerbach ${ }^{2}$
}

\begin{abstract}
Resumo: O presente ensaio teórico de abordagem qualitativa e naturezas bibliográfica e documental tem como objetivo analisar e compreender as configurações da escola normal e os indícios relativos à educação no final do século XIX no Brasil, a partir das representações realizadas pelo escritor cearense Adolfo Caminha no romance A Normalista, de 1893. Para tanto, oferece-se um panorama teórico sobre os diálogos entre história e literatura, bem como sobre a instituição das escolas normais no período final do Império até os primeiros anos da República, recorte temporal pregresso e coevo a época de publicação da obra. Posteriormente, fazemos uma análise à luz da literatura especializada a partir de alguns excertos do livro. Ao fim, indica-se um horizonte de possibilidades para a escrita e para a construção do pensamento historiográfico na educação brasileira, realizado com a interseção entre a história e a literatura.

Palavras-chave: História da Educação Brasileira. História e Literatura. Escola Normal.

\section{DIALOGUES BETWEEN THE HISTORY OF EDUCATION AND LITERATURE: THE NORMAL SCHOOL IN ROMANCE A NORMALISTA, BY ADOLFO CAMINHA (1893)}

\begin{abstract}
The present theoretical essay with a qualitative approach and bibliographic and documentary nature aims to analyze and understand the configurations of the normal school and the indications related to education at the end of the 19th century in the Brazil, based on the representations made by Ceará writer Adolfo Caminha in the novel A Normalista, from 1893. For this purpose, a theoretical overview of the dialogues between history and literature is offered, as well as about the institution of normal schools in the late Empire until the early years of the Republic, a preceding time frame and the time of publication of the work. Subsequently, an analysis is made in the light of specialized literature based on some excerpts from the book. In the end, a horizon of possibilities is indicated for writing and for the construction of historiographic thought in brazilian education, carried out with the intersection between history and literature.
\end{abstract}

Keywords: History of Brazilian Education. History and Literature. Normal School.

\section{DIÁLOGOS ENTRE LA HISTORIA DE LA EDUCACIÓN Y LA LITERATURA: LA ESCUELA NORMAL EN ROMANCE A NORMALISTA, DE ADOLFO CAMINHA (1893)}

Resumen: El presente ensayo teórico con enfoque cualitativo y de carácter bibliográfico y documental tiene como objetivo analizar y comprender las configuraciones de la escuela normal y las indicaciones relacionadas con la educación a fines del siglo XIX en Brasil, a partir de las representaciones realizadas por el escritor cearense Adolfo Caminha en la novela A Normalista, desde 1893. Para ello, se ofrece un repaso teórico de los diálogos entre historia y literatura, así como sobre la institución de las escuelas normales en el Imperio tardío hasta los primeros años

\footnotetext{
${ }^{1}$ Licenciado em História e Mestre em Educação (UFV). E-mail: derossi.caio@gmail.com.

2 Doutora em Educação (UFSCar). Professora Adjunta do Departamento e do Programa de PósGraduação em Educação (UFV). E-mail: joana.germano@ufv.br.
} 
de la República, un marco temporal anterior y la época de publicación de la obra. Posteriormente, se realiza un análisis a la luz de la literatura especializada a partir de algunos extractos del libro. Al final, se indica un horizonte de posibilidades para la escritura y para la construcción del pensamiento historiográfico en la educación brasileña, realizado con la intersección entre historia y literatura.

Palabras clave: Historia de la Educación Brasileña. Historia y Literatura. Escuela normal.

\section{Palavras iniciais}

O presente ensaio teórico de abordagem qualitativa e naturezas bibliográfica e documental, tem como objetivo analisar e compreender as relações entre a história e a literatura, explorando as possibilidades para o trabalho historiográfico, enfocando em especial a obra A Normalista, de Adolfo Caminha do ano de 1893. Assim, o recorte adotado insere-se no campo da História da Educação Brasileira por pensar as dinâmicas do ensino normal na obra literária. O artigo apresenta a discussão da literatura enquanto fonte, objeto e aporte para o trabalho do historiador, bem como as possibilidades de experimentar as dinâmicas da escrita literária na apresentação e sistematização das ideias empreendidas na investigação histórica.

Como justificativa do artigo e sinalização que direciona para a relevância do objeto de estudo e das considerações acerca dos campos temáticos, apresentaremos um levantamento das produções acerca da obra literária e suas relações. Para tanto, foi realizada uma busca no Banco de Teses e Dissertações da CAPES, por se entender que demais produções como artigos, são derivados, em muitos casos de produções dos programas de pós-graduação. Outra razão que justificou a escolha, se dá pelo panorama que pode ser feito em termos de critérios dos tipos de produção, no caso teses e dissertações, o recorte temporal, bem como a área de concentração. Cumpre destacar que o levantamento apresentado não é o objeto central de análise no artigo. Entretanto, o estado do conhecimento oferece uma mirada panorâmica acerca das investigações sobre a temática, além de corroborar com a justificativa que sublinha a relevância da proposição.

Com o termo de busca "a normalista", eleito em razão de ser a fonte base para as reflexões propostas, foram encontrados um total de 16 resultados, sendo 11 dissertações e 5 teses. As áreas de concentração se subdividem Letras, com 6 dissertações; Educação, com 1 dissertação e 3 teses; História, com 2 dissertações e 1 tese; Sociologia, com 1 dissertação e 1 tese e Ciência da Informação, com 1 dissertação. As produções se deram entre os anos de 1995 e 2018, de forma ininterrupta. 
Em termos das instituições onde os trabalhos foram veiculados e desenvolvidos, a Universidade Federal do Ceará (UFC) abrigou a maior parte das produções, 5, seguida da Universidade Federal de Uberlândia (UFU), com 2 trabalhos. Já a Universidade Federal do Amazonas (UFAM), a Universidade do Estado da Bahia (UNEB), a Universidade Estadual Paulista (UNESP), a Universidade de São Paulo (USP), a Universidade Federal de Pernambuco (UFPE), a Universidade Federal de Pelotas (UFPel) e as Pontifícias Universidades Católicas, de São Paulo, Minas Gerais e Rio Grande do Sul, respectivamente PUCSP, PUCMG e PUCRS, detêm um trabalho cada.

Como primeiras impressões, podemos supor que a maior concentração de pesquisas na UFC tenha como razão a origem do autor e as representações da sociedade e cidades do estado do Ceará. Outra identificação geral que pode ser afirmada, é que os trabalhos do campo da Letras, enfocam mais a obra literária em si, discutindo seus diferentes matizes, enquanto as outras áreas fazem, discutem a partir de recortes ou exemplos da obra literária, outras questões postas. Portanto, os trabalhos selecionados, mais dialogam do contexto e dos sujeitos envolvidos no período e na Escola Normal, que o livro em si.

Para o presente artigo, foram analisados os trabalhos dos campos da Educação e da História, no sentido da inserção do texto ser no campo da História da Educação. Portanto, foram evidenciados um total de 7 produções, sendo 3 dissertações, 2 de História e 1 da Educação; e 4 teses, 1 de História e 3 da Educação. Cumpre ressaltar que as análises dos trabalhos seguiram a interpretação e a compreensão dos títulos, dos resumos e, quando necessário, das introduções e/ou considerações finais.

Considerando os trabalhos do campo da Educação, a dissertação de Ronaldo Antônio Pereira da Silva, intitulada "Do mestre-escola à normalista: gênese da profissão docente em Sergipe (1870-1911)", do ano de 2007, trata do contexto explicitado no livro e dos professores da educação primária e formados na Escola Normal, entre o Império e a República. A tese de Helena de Lima Marinho Rodrigues de Araújo, com o título "A tradicional escola normal cearense chega ao bairro de Fátima: formação das primeiras professoras primárias (1958 - 1960)”, de 2014, evidencia a formação docente para o nível primário a partir das escolas normais, em um recorte temporal distinto do explicitado no livro de Caminha.

A tese "A Escola Normal Regional Imaculada Conceição em Pelotas/RS: a atuação da igreja católica e dos poderes públicos (1955-1971)", de Magda de Abreu Vicente, produzida no ano de 2018, retoma as tensões entre interesses de governo e 
religiosos em torno de uma escola normal, já no período republicano. E o trabalho de doutorado "Ser e fazer-se professora no Piauí no século XX: a história de vida de Nevinha Santos", de Jane Bezerra e Sousa, do ano de 2009, trata uma narrativa de trajetória de vida de uma professora, que teve o ensino normal como um dos espaços de formação e atuação. Assim, como supracitado, percebe-se que a correspondência com o termo "a normalista" nas pesquisas em Educação, remontam mais as instituições de ensino e o segmento da escola normal, que a obra literária em si.

Refletindo sobre os três trabalhos desenvolvidos no campo da História, um movimento distinto ao último citado, oferece a tônica dos trabalhos, em alguma parte. A dissertação de Eliana Evangelista Batista, sob o título "A Normalista como interseção: escola, literatura, imprensa e estratégias políticas no Estado Novo (Alagoinhas / 19371945)", do ano de 2012, já retoma uma experiência com a obra literária, marcando um caráter interdisciplinar e localizado no período mais sensível da ditadura varguista, evidenciando as apropriações e os interesses em relação ao livro e as representações preconizadas sobre a docência.

Já a dissertação "Personagens Negras: Tigres, Gajeiros e Domésticos na obra de Adolfo Caminha nos fins do século XIX”, de Silvia Helena Nascimento, produzida em 2000, propõe uma análise imbuídas das questões étnico-raciais, acerca das representações de personagens negros do autor da obra preconizada, figurando a protagonista Maria do Carmo, mas não enfocando à docência como objeto central. Por fim, a tese "Entre o mutualismo e o sindicalismo: a resistência solidária dos trabalhadores portuários de Fortaleza (1912-1933)", de Nagila Maia de Morais, produzida no ano de 2017, figura na pesquisa em relação a formação em nível primário dos trabalhadores, segmento que atuavam as formadas na Escola Normal, bem como o apoio delas a esses sujeitos. Mas, os objetivos da pesquisa não circulavam sobre as questões educacionais em si.

Destarte, o que pode ser identificado é que os trabalhos do campo da História e da Educação, se debruçam mais sobre o contexto temporal e sobre as categorias de trabalho e de sujeitos, que em relação a obra em si. Talvez, essa consideração seja um truísmo, quando se retoma as áreas epistemológicas, entretanto não deixa de ser indiciosa, para considerar o trabalho interdisciplinar entre os campos de conhecimento, nesse caso o ensino de História, a partir do uso da literatura enquanto fonte e objeto de análises. 
Para tanto, em termos de organização do texto, além da parte introdutória e de considerações finais, o presente artigo é dividido em três momentos: o primeiro estabelece uma visada panorâmica e teórica sobre os diálogos entre história e literatura. É destacado o papel da corrente da História Cultural nesse quadro, por representar uma mudança na escrita historiográfica, nas formas de investigação e nos objetos alvo de estudos. O interesse pelas representações e imaginários construídos a partir do mundo concreto ganham enfoque.

Já o segundo momento propõe um arrazoado da trajetória da escola normal no país, entre os períodos do Império e da República, com a finalidade de apresentar os percursos e as reformas legais nas instituições. A terceira parte é dedicada para uma breve apresentação da obra literária e de seu autor, explicitando as relações entre as personagens e a representação da escola normal. Ao fim, o trabalho propõe um balanço das possibilidades de interseção entre literatura e história, pensando na reflexão e no horizonte aberto a interlocuções no campo da história da educação.

\section{Diálogos entre a História da Educação e a Literatura}

A presente seção objetiva apresentar uma visada panorâmica sobre alguns autores que discutem as relações entre história e literatura. Baseados na proposta da História Cultural, evidencia-se os contatos e possibilidades de interação da literatura como objeto, aporte e fonte para o trabalho histórico. Precisa-se destacar também que, as diferenciações entre os campos de estudo também foram dispostas, com a finalidade de tencionar os horizontes de uma relação.

Segundo Pesavento (2006) as produções que apostavam em um diálogo entre história e literatura, refletindo sobre as relações com as fontes e sobre a própria escrita historiográfica, emergem no Brasil na década de 90 do século XX, em razão das contribuições da História Cultural e das revisões na produção dos historiadores que passam a considerar novos temas, objetos, territórios e teorias para subsidiar a construção de conhecimento histórico. No que se refere à História Cultural e as relações entre história e literatura, Pesavento (2004) dispõe que para além de questões epistemológicas idiossincráticas de cada campo, pode-se pensar em aproximações e distanciamentos no que se refere à representação do mundo vivido.

A história e a literatura, cada uma de sua forma, utilizam meios retóricos e narrativos para dissertar sobre o presente, o passado e pensar em horizontes futuros. As 
duas áreas também abordam questões centrais do seu contexto histórico de produção e se destinam à interlocutores, à leitores específicos. Entretanto, como destaca Pesavento (2004), na história temos a utilização de um método para a análise e a compreensão das fontes, dentre suas variedades, buscando a maior proximidade com os acontecimentos, o que é uma diferenciação com relação à literatura, que se compromete com o ficcional. Ainda sobre as diferenças entre os dois campos, Borges (2010) entende a história como um processo social e disciplina acadêmica, enquanto a literatura uma expressão artística, de características próprias, que por ser produto e produtora das relações coevas ao seu tempo, podendo ser objeto e fonte para o trabalho historiográfico.

Santos (2007) compreende que os estudos acerca das relações entre história e literatura são possibilitados graças a indagações epistemológicas que sinalizam para convergências e divergências entre os campos do conhecimento. O primeiro, de sinalização metodológica, indica uma aproximação que é quanto à escrita historiográfica, que já foi destacada anteriormente. A questão que se tenciona são os arranjos organizados entre os acontecimentos do passado e as narrativas dos pesquisadores.

Mesmo sabendo do rigor do método e da análise crítica e contida nos documentos, que são os fatores que residem na segunda questão, a epistemológica, e no crédito dado aos documentos para se entender o passado. Os fatos pretéritos são irrecuperáveis, cabendo ao historiador o uso de recursos retóricos para sistematizar e apresentar aquele objeto de estudo, sendo passível por parte do público e dos pares, a revisão e a reescrita das narrativas. Pesavento (2006) afirma que a linguagem, em suas distintas manifestações, é forma de expressão e de significação das relações entre os seres humanos e o mundo, sendo a história e literatura, formas hereditárias de explicação do que se vive, variando conforme o tempo e o espaço.

Para Sevcenko (2003, p. 28) a literatura “[...] constitui possivelmente a porção mais dúctil, o limite mais extremo do discurso, o espaço onde ele se expõe por inteiro, visando reproduzir-se, mas expondo-se igualmente à infiltração corrosiva da dúvida e da perplexidade", sendo então, passível de reflexão sobre as questões sociais, evidenciando portanto, a relação estreita e fortuita do campo literário com as demais vertentes das ciências humanas. $\mathrm{O}$ autor ainda destaca algumas diferenciações entre a história e literatura: enquanto a primeira se ocupa com as estruturas sociais, com a realidade, a segunda se preocupa com a possibilidade, com o vir a ser. Ainda assim, Sevcenko 
(2003) sublinha que tais características literárias não impedem o seu uso pelos historiadores.

Cumpre ressaltar que tanto a história quanto a literatura têm características e distinções próprias, não cabendo aqui um reducionismo ou relação semântica sinonímica. Mas, entendendo os sentidos ficcionais e representativos da obra literária, o historiador pode se interrogar quanto aos papéis e aos contextos de produção que retomam as condições sociais, políticas, econômicas e históricas. A esse respeito, Pesavento afirma que:

a sintonia fina de uma época, fornecendo uma leitura do presente da escrita, pode ser encontrada em um Balzac ou em um Machado, sem que nos preocupemos com o fato de Capitu, ou do Tio Goriot e de Eugène de Rastignac, terem existido ou não. Existiram enquanto possibilidades, como perfis que retraçam sensibilidades. Foram reais na "verdade do simbólico" que expressam, não no acontecer da vida. São dotados de realidade porque encarnam defeitos e virtudes dos humanos, porque nos falam do absurdo da existência, das misérias e das conquistas gratificantes da vida. (PESAVENTO, 2006, p. 2-3)

Dessa forma, embora a narrativa seja ficcional e repleta de recursos linguísticos e literários com finalidades tácitas para diálogo com os leitores, tais histórias podem ser compostas por recursos de verossimilhança com o cotidiano e representar as questões, os debates e os contextos de seu autor e de sua época de produção.

Chartier (2009) tenciona as perspectivas de relação entre a história e a literatura também em dois pontos que sinalizam convergências e divergências. O primeiro deles estreita a relação entre as áreas. Aprofunda um elemento trazido pelos demais autores apresentados, em razão de seus trabalhos sobre a história do livro, da leitura e das publicações, ao demonstrarem que expressões artísticas como o teatro e a literatura se apropriam de teorias historiográficas para a sua composição. Nesse sentido, mesmo que em um desenho ficcional, os romances do século XIX e as peças teatrais dos séculos XVI e XVII, por exemplo, se utilizam de recursos da verossimilhança, tratando sobre personagens e representações já existentes.

Isso quer dizer que, mesmo sendo obras ficcionais, os contextos, os aspectos históricos e coletivos do tempo de sua produção, estão presentes nas obras. Contudo, Chartier (2009) dispõe a existência do compromisso social e científico da história na produção e na chancela ou não de discursos. Essa marcação é importante para sinalizar os percursos procedimentais da produção, da crítica e das (re)interpretações dos objetos históricos, que surgem em contextos de emergência de narrativas autoritárias, revisionistas, negacionistas e nacionalistas, por exemplo. 
Burke (1992) compreende que o abandono da forma retórica empobreceu o processo de escrita historiográfica. As narrativas muito relacionadas ao modo de escrever dos historiadores metódicos, considerados positivistas, de descrição densa e de proposição de grandes histórias oficiais e políticas, foram esquecidas, em razão do estudo de outras perspectivas para a produção de conhecimento histórico, sendo retomadas a partir dos anos de 1980.

Nesse momento identificamos a possibilidade de narrativas em dimensões micro, local, regional e a ocupação de novos objetos, sujeitos e teorias para a construção historiográfica. Assim, Burke (1992) considera que a interseção entre a história e a literatura pode se processar para além de relações enquanto fontes, problemas de estudo, podendo contribuir para a escrita histórica, conjugando estilos e recursos literários para a apresentação e sistematização das investigações.

Para Ribeiro (2000) a literatura coaduna vários processos de produção em um produto que é social, vivo e dinâmico, que possui materialidade, bem como possibilidade de diálogo e de trocas com os seus produtores, objetivos e interlocutores. Nessa direção, Chartier (1994) assevera que os textos literários compreendem uma teia relacional de sentidos e significados atribuídos pelos sujeitos que interagem com eles inseridos em um espaço e tempo específicos, reiterando que:

as obras - mesmo as maiores, ou sobretudo, as maiores - não têm sentido estático, universal, fixo. Elas estão investidas de significações plurais e móveis, que se constroem no encontro de uma proposição com uma recepção. Os sentidos atribuídos às suas formas e aos seus motivos dependem das competências ou das expectativas dos diferentes públicos que delas se apropriam. Certamente, os criadores, os poderes ou os experts sempre querem fixar um sentido e enunciar a interpretação correta que deve impor limites à leitura (ou ao olhar). Todavia, a recepção também inventa, desloca e distorce. (CHARTIER, 1994, p. 4)

Portanto, Ribeiro (2000) destaca que existe um movimento dialético na relação entre os leitores e o texto literário, no sentido que permite a chegada a diferentes sínteses, em razão dos diversos entendimentos e de uma relação de coautoria assumida, por quem dialoga. Darnton (1992) entende em perspectiva paralela a Burke (1992) que os diálogos entre história e literatura podem impactar a escrita historiográfica, propondo um convite para a participação ativa do leitor.

A literatura enquanto fonte histórica, pode ser utilizada de modo a se pensar nos indícios, nos rastros deixados pelas representações e linguagens diversas, próprias de uma época, de uma espacialidade e de temporalidades. Pesavento (2006) ainda aponta 
que a literatura e as suas mobilizações de verossimilhança e de incorporação de histórias e de teorias em suas obras podem ser um aporte para a análise e compreensão críticas das fontes. Assim, ressaltando as possibilidades da literatura enquanto material e objeto de estudo para a história, Borges afirma que:

no universo amplo dos bens culturais, a expressão literária pode ser tomada como uma forma de representação social e histórica, sendo testemunha excepcional de uma época, pois um produto sociocultural, um fato estético e histórico, que representa as experiências humanas, os hábitos, as atitudes, os sentimentos [...] e as questões diversas que movimentam e circulam em cada sociedade e tempo histórico. A literatura registra e expressa aspectos múltiplos do complexo, diversificado e conflituoso campo social no qual se insere e sobre o qual se refere. Ela é constituída a partir do mundo social e cultural, e, também, constituinte deste. (BORGES, 2010, p. 98)

Desse modo, em consonância com os objetos e preocupações da História Cultural, Pesavento (2004) analisa que a compreensão do espírito da época, das relações interpessoais, das regras e configurações da sociedade, dos modos de se alimentar ou de se vestir, são dentre alguns elementos, possibilidades que a literatura desvela para o exercício de escrita da história. Darnton (1986) chama atenção que o estudo da obra literária deve se atentar para as suas edições, para as questões linguísticas do idioma e da região de origem, as mudanças geradas ao longo do tempo e a existência ou não de uma tradição oral que se envolve entre os sujeitos e as narrativas, estão como alguns pontos que devem ser observados pelos pesquisadores. $\mathrm{O}$ autor ainda destaca que a depender do objeto de estudo, podem ocorrer problemas de indefinições em datas e a possibilidade maior ou menor de pensar as relações entre os sujeitos e as histórias contadas.

Um ponto que vale a ressalva é feito por Abud, Silva e Alves (2011) no trabalho entre a história e a literatura. Os autores apontam que não se pode cobrar especificidades do trabalho historiográfico na obra literária e vice-versa. Do mesmo modo, a produção de conhecimento não deve ser feita de forma estanque, pinçando elementos convenientes em detrimento de uma análise global, contextualizada. A linguagem e seus recursos precisam ser entendidos, bem como sua localização e críticas frente à escola literária, suas hierarquizações e as teorias vigentes da época. O processo de historicizar o texto literário envolve refletir sobre as interações sociais, as tensões e contradições presentes na obra e na época.

Portanto, em razão da presença e das interlocuções colocadas entre os sujeitos, os tempos e as produções, é imperativo pensar que a história, a literatura e a cultura 
sejam indissociáveis. Destarte, buscou-se apresentar um panorama teórico das interseções entre história e literatura. Embora as particularidades e as distinções de cada campo, apontou-se os elementos de toque, oferecendo possibilidades de trabalho e marcando a linha tênue das relações entre a escrita, os objetos e os aportes da história e da literatura.

\section{Considerações acerca das Escolas Normais}

A presente seção faz uma visada histórica e panorâmica entre as décadas finais do Império e os primeiros anos da República, que marcam a implementação e as principais reformas sofridas pelas escolas normais. O recorte temporal foi escolhido em um sentido de longa duração, para que fossem percebidas as nuances e as trajetórias históricas que antecederam e foram coevas ao ano de publicação da obra literária enfocada no trabalho.

A Reforma Leôncio de Carvalho, que é homônima ao Ministro de Estado de Negócios do Império, foi a responsável por instaurar a Escola Normal na Corte. Assim, pela força do Decreto $n^{\circ}$ 7.247, de 1879 (BRASIL, 1879), marca-se a mudança na reestruturação dos ensinos primário, secundário e superior no contexto imperial do final da década de 70, do século XIX, denotando que a instrução, além de ser um elemento por si só modernizante, deveria acompanhar as modificações legais trazidas pelos novos Códigos Comercial (1850) e de Processo Criminal (1832), bem como pela Lei do Ventre Livre (1871).

Com o Ato Adicional de 1834, percebe-se um movimento de descentralização do poder central imperial com o ensino elementar, legando a responsabilidade de sua oferta para cada província. Duas foram as exceções para a normativa legal: o Rio de Janeiro, que por ser a capital do Império, continuou sob comando central do governo, bem como, as faculdades isoladas de Medicina e Direito. Em razão do Ato Adicional, cada província, em seu tempo, começou a instaurar instituições voltadas para a formação de professores: as escolas normais.

Kulesza (1998) destaca que no caso fluminense, Niterói já ganha a sua primeira escola normal em 1835 e em termos mais globais do Império, depois da homologação da Reforma Leôncio de Carvalho, a formação docente passa a ocorrer seguindo o modelo dos estabelecimentos normais de ensino. Cabe destacar que até 1879, os professores eram formados nos liceus, entidades características pela oferta de um ensino 
técnico-profissionalizante, a partir de um acréscimo curricular de disciplinas pedagógicas.

O primeiro conjunto de normativas para a Escola Normal foram publicadas no Decreto $n^{\circ} 8.025$ de 1881 (BRASIL, 1881) e estabelecia as garantias e deveres de discentes e funcionários, bem como os modos de ingresso, o regime de externato e a sua gratuidade. $\mathrm{O}$ objetivo era a formação de professores e professoras para a atuação no ensino primário em duas áreas: Ciências e Letras e Artes. As disciplinas eram distribuídas em quatro módulos e ambas as áreas tinham cursos de Ensino Religioso e Francês como eletivos.

O curso de artes possuía currículo mais conciso e era composto pelas matérias de caligrafia, desenho, ginástica e música, tendo para as mulheres a cadeira específica de trabalhos manuais com agulhas, em razão dos afazeres de costura e de bordado, por exemplo. Já o curso de ciências e letras possuía a grade mais extensa e eram compostos pelas disciplinas de português, matemática elementar, lógica e direitos natural e público, pedagogia, economias social e doméstica, agricultura, história e geografia gerais e do Brasil, mecânica, astronomia, ciências biológicas e físicas.

Um novo estatuto foi aprovado em 1888, por força do Decreto $\mathrm{n}^{\mathrm{o}} 10.060$ (BRASIL, 1888), estabelecendo que as escolas normais deveriam ter ginásios e escolas de aplicação, divididos por sexo, para que os docentes em formação pudessem exercer a regência e as práticas pedagógicas. $O$ trabalho nos jardins da infância era exclusivo das mulheres, marcando a prática do cuidado e da instrução como indissociáveis e definidos como função feminina.

O mesmo Decreto de 1888 também previa a instalação de bibliotecas, laboratórios de ciências, museus pedagógicos, salas de desenho e oficinas nas instituições de ensino normal. A normativa 10.060 de 1888 estava em consonância com a Reforma Leôncio de Carvalho, que já prescrevia a presença de bibliotecas e de museus pedagógicos nos estabelecimentos de formação docente. É percebida uma tentativa de propor atividades consideradas práticas, destinadas ao teste e ao treinamento de métodos e práticas pedagógicas, bem como a construção de saberes considerados empíricos. Para os alunos do terceiro módulo da escola normal, visitas técnicas e estágios supervisionados já eram previstos, para refletir as questões das escolas primárias. O plano, que não foi cumprido, era de construir um museu e uma biblioteca em cada instituição. Kulesza (1998) indica que no caso de escolas de capitais, 
como no Rio de Janeiro, os alunos poderiam frequentar outras bibliotecas e museus que pertencessem ao aparato imperial, como o Museu Nacional, por exemplo.

Autores como Men e Neves (2007), Faria Filho (2000) e Souza (1998) indicam que a década de 1870 marca uma diferenciação nas metodologias e práticas de ensino que, até então, seguiam o método Lancaster e/ou Mútuo, que utilizavam dos monitores, alunos considerados mais desenvolvidos e conscientes da matéria, o ensino de leitura e escrita para aqueles com maior dificuldade e/ou atraso, aplicado desde 1827, ano que data a primeira lei imperial a versar sobre a instrução. A mudança se inscreve no uso do método intuitivo, também denominado de lição das coisas, que calcado na observação, medida, comparação e identificação dos objetos para assim, construírem o processo de ensino-aprendizado. Nesse sentido, a preconização de atividades práticas, estabelecimento de oficinas, museus, bibliotecas e gabinetes de desenho, são alguns exemplos concernentes ao novo paradigma pedagógico.

As normas da escola normal de 1888 alteraram a composição curricular chancelada pelo Decreto em 1881. Em termos de continuidade, havia uma separação de disciplinas entre homens e mulheres, no que se refere a exercícios físicos, militares, manuais, mercantis, agricultura e horticultura para os primeiros e atividades de corte, costura, bordado e jardinagem para o sexo feminino. No que diz respeito às disciplinas, Ensino Religioso e o Francês passaram a ser obrigatórios, junto com Português, Literatura, História, Geografia, Economia Política, Pedagogia e Legislação Escolar, Moral e Cívica, Álgebra, Geometria, Aritmética, Escrita, Música, Ginástica, Física, Botânica, Geologia, Química e Zoologia.

A Secretaria de Estado de Negócios da Instrução Pública, Correios e Telégrafos foi criada em 1890, com o advento da República, e tinha como atribuição reformar e reestruturar o ensino, afastando as lembranças imperiais e aproximando ideologicamente os pressupostos republicanos. Desse modo, o Decreto $\mathrm{n}^{\circ}$ 982, de 1890 (BRASIL, 1890) empreendeu mudanças nos currículos da escola normal, acrescentando as disciplinas de moral e sociologia. Em 1892, a Lei no 85 (BRASIL, 1892) permitiu a municipalização das instituições normais e a responsabilidade do governo central com a educação primária.

Destarte, pode-se perceber neste sintético panorama que, embora pareça um truísmo, é interessante ressaltar que a organização da instrução e da formação de professores estiveram ligados aos distintos ideários de Estado, com suas organizações, bem como a ideias de modernização. A formação tinha uma clivagem de gênero, 
reforçando representações e práticas do que (não) seria próprio do masculino e do feminino. Entende-se ainda que se tinha uma formação em termos de ofício para que os professores pudessem ensinar, demarcando a lógica do trabalho, principalmente para os mais pobres, levando em consideração as discrepâncias no acesso, na permanência e no prosseguimento dos estudos nos períodos retratados.

\section{Apresentação da obra, do autor e das disposições de diálogos}

A presente seção abordará de forma sintética a obra e o seu autor, para posteriormente fazer uma articulação dos indícios das questões educacionais, principalmente no que se refere à escola normal, com as outras dimensões da sociedade. Nesse sentido, visa-se explicitar, dentro do que já fora apresentado com relação às interseções entre história e literatura e das trajetórias da escola normal, os rastros e as pistas das críticas e do enredo que a educação permeia. Vale destacar que os excertos da obra analisada corroboram com a interpretação oferecida pelo recorte do texto, além do diálogo com a literatura especializada.

Segundo Coutinho (2004) em relação ao autor, Adolfo Ferreira dos Santos Caminha, nascido em 1867 e falecido em 1897, vítima de tuberculose, foi, em ordem cronológica, o último autor a escrever filiado à Escola Naturalista. Cearense, natural de Arati, estudou na Escola Naval no Rio de Janeiro. Desde os tempos de formação militar, em um contexto imperial, já se posicionara contrário à escravidão e favorável ao regime republicano. Com 18 anos tornou-se Guarda da Marinha e regressa a Fortaleza. Em função de um envolvimento amoroso com uma moça já casada, foi alvo de várias censuras da sociedade da época, acabando assim, por não se estabelecer na Marinha. Com o advento da República, ele foi o convidado a fazer o discurso local em defesa da nova forma de governo. Depois da ocasião, se dedicou ao funcionalismo público residindo durante um período na Europa.

O romance A Normalista, publicado originalmente em 1893, reflete as insatisfações e as críticas à sociedade cearense do século XIX, permitindo notar a denúncia feita às instituições sociais como uma das características próprias do naturalismo e uma resposta pessoal do autor frente à sua própria trajetória. O livro narra a história da personagem Maria do Carmo, uma menina pobre do interior que após a morte da mãe em razão das fortes secas e da migração do pai para a região norte do país, em busca de melhores condições de vida, é criada por João da Mata, uma espécie 
de padrinho, amigo da família que morava em Fortaleza e poderia, junto de sua esposa Terezinha, oferecer oportunidade de estudo e de desenvolvimento para a família.

Assim, Maria do Carmo foi escolarizada em uma instituição confessional até a sua entrada na escola normal, para se formar como professora do primário. Com o passar dos anos e com as transformações corporais próprias da juventude, João da Mata desperta um desejo pela moça, não a deixando namorar Zuza, filho de um dos coronéis da região que estudava direito na capital pernambucana. Caminha retrata que a cidade comenta maliciosamente o envolvimento dos jovens, gerando desaprovação do pai do rapaz, somado à perseguição empreendida pelo padrinho de Maria do Carmo.

João da Mata se separa de Dona Terezinha que percebera as intenções dele para com a afilhada e aproveita um momento de fragilidade de Maria do Carmo, sensibilizada com a partida de Zuza, para conseguir a consumação do ato sexual. A normalista fica grávida e para evitar um escândalo maior vai para o interior, na casa de familiares de João da Mata. O bebê morre durante o parto e Maria do Carmo volta para Fortaleza, onde se casa com o personagem Alferes Coutinho, conseguindo a remissão da sociedade, que outrora a condenou moralmente.

Cumpre destacar que com relação à escola literária do Naturalismo, ela surge em contexto europeu no século XIX no contexto das transformações dos modos de produção do sistema capitalista e presença das classes burguesa e proletária. Segundo Cândido e Castelo (1974), o naturalismo se distingue do realismo, mesmo compartilhando críticas à sociedade. $O$ primeiro, por influência das teorias científicas de Taine, Darwin e Comte, buscava explicar os comportamentos humanos a partir da prevalência de fatores externos e determinantes em suas ações.

Nesse sentido, os personagens são animalizados e sobrepostos a características biológicas em detrimento de uma constituição de um perfil psicológico, baseado em outros sentimentos. Coutinho (2004) aponta como principais representantes da escola Naturalista, além de Adolfo Caminha, Aluísio de Azevedo, Inglês Souza e Júlio Ribeiro no contexto nacional, e Émile Zola no contexto francês.

Após breve apresentação do autor, da obra e da escola literária filiada, para situar contextualmente os sentidos de produção, passar-se-á aos comentários de alguns trechos da obra pensando as relações educacionais e sociais relacionadas, a partir de um prisma da história da educação. Nesse sentido, à luz da literatura especializada, são oferecidos alguns comentários sobre os excertos selecionados, situando-os também no enredo do romance. 
O narrador traz alguns entendimentos sobre a educação feminina no século XIX, principalmente ao que se refere a Escola Normal, trazendo as cores da sociedade cearense e seus pensamentos com relação a pedagogia e a figura das normalistas.

A educação feminina (...) é um mito ainda não compreendido pelos corifeus da moderna pedagogia. Queríamos introduzir no Ceará os dissolventes costumes parisienses a fortiori, mas não eram essas as tendências do nosso povo essencialmente católico e essencialmente crédulo. Não admitia a teocracia tal como aceitavam os padres - "essa corja de especuladores" - mas era preciso respeitar as crenças populares, o verdadeiro sentimento religioso sem hipocrisia, sem preconceitos. (...) O que é a Escola Normal, não me dirão? Uma escola sem mestres, um estabelecimento anacrônico, onde as moças vão tagarelar, vão passar o tempo a ler romances e maldizer o próximo, como vocês sabem melhor que eu...José Pereira contestou, lembrando o Berro, "uma ilustração invejável", o padre Lima "um excelente educador em cujas aulas as raparigas aprendiam ao mesmo tempo a ciência e a religião" - Mas não têm método, não fazem caso daquilo, vão ali por honra da firma, por amor aos cobres, rebateu Elesbão, forcejando por falar alto. Aquilo é uma sinecura, não temos educadores, é o que é. (CAMINHA, 2001, p. 203-204)

Percebe-se aqui o autor tomando Paris como modelo de modernidade, algo que marcou os últimos anos do século XIX e o início do século XX. Desde os costumes, como se percebe nas linhas do romance, até a arquitetura das cidades, como nas reformas urbanas do Rio de Janeiro, era necessário enquadrar o país nos moldes da Belle Époque (CHALHOUB, 2001). Tal enquadramento era fundamental para adequar a república à modernidade e seus costumes.

O excerto que segue também é uma fala do narrador-onisciente que trata um pouco da rotina de Maria do Carmo e sua amiga Lídia, em um contexto posterior ao ingresso na escola normal.

Havia meses que Maria do Carmo cursava a Escola Normal. Sua vida traduziase em ler romances que pedia emprestados a Lídia, toda preocupada com bailes, passeios, modas e tutti quanti... Ia à Escola todos os dias vestidinha com simplicidade, muito limpa, mangas curtas evidenciando o meio-braço moreno e roliço, em cabelo, o guarda-sol de seda na mão, por ali afora - toque, toque, toque - até à praça do Patrocínio, como uma grande senhora independente. (CAMINHA, 2001, p. 16-18)

Hábitos refinados e comportamentos higiênicos compunham o figurino republicano. A despeito de toda desigualdade social, herança do passado escravista recente, e de toda superficialidade dos modos, era muito bem vista a obediência à moda por parte das moças de família. A personagem, ao se manter bem vestida e limpinha, retrata o ideal feminino desejado. 
Ainda sobre os hábitos de Maria do Carmo e das outras normalistas, com relação aos hábitos de leitura, o narrador descreve que

Maria folheou ao acaso aquela obra-prima, disposta a devorá-la. E, com efeito, leu-a de fio a pavio, página por página, linha por linha, palavra por palavra, devagar, demoradamente. (...) Que regalo todas aquelas cenas de vida burguesa! Toda aquela complicada história do Paraíso! ...A primeira entrevista de Basílio com Luiza causou-lhe uma sensação estranha, uma extraordinária superexcitação nervosa; sentiu um como formigueiro nas pernas, titilações em certas partes do corpo, prurido no bico dos seios púberes; o coração batia-lhe apressado, uma nuvem atravessou-lhe os olhos...Terminou a leitura cansada, como se tivesse acabado de um gozo infinito...E veio-lhe à mente o Zuza: se pudesse ter uma entrevista com o Zuza e fazer de Luiza...(CAMINHA, 2001, p. 40)

Até aquela data [Maria do Carmo] só lera romances de José de Alencar, por uma espécie de bairrismo mal entendido, e a Consciência de Heitor Mallot publicada em folhetins na Província. A leitura do Primo Basílio despertou-lhe um interesse extraordinário. 'Aquilo é que é um romance. A gente parece que está vendo as coisas, que está sentindo...' (CAMINHA, 2001, p. 34)

Entretanto, a leitura não estava apenas relacionada a um passatempo, enfocada apenas nos aspectos literários, mas sim, como fonte e base de conhecimentos, pautados em um processo que enfoca a memorização e o apelo do conteúdo, sem críticas aos processos e objetos. Assim, o narrador descreve as relações em sala de aula e o professor de Maria do Carmo:

O professor pediu um compêndio que folheou de relance. Qual era a lição? A Oceania? Pois bem...

-Diga, senhora D. Maria do Carmo: a Oceania é ilha ou continente?

Maria fechou depressa o compêndio que estivera lendo, muito embaraçada e, fitando o mestre, batendo os dedos na carteira, com um risinho:

- Somente uma parte da Oceania pode ser considerada um continente.

- Perfeitissimamente bem!

E perguntou, radiante, como se chama essa parte da Oceania que pode ser considerada continente; explicou demoradamente e categoricamente a natureza das ilhas australianas, elogiando as belas paisagens claras da Nova Zelândia, a sua vegetação opulenta, as riquezas do seu solo, o seu clima, a sua fama, com entusiasmo de turista, animando-se pouco e pouco, dando pulinhos intermitentes na cadeira de braços que gemia ao peso de seu corpo. (CAMINHA, 2001, p. 71)

Para Saviani (2012), o estudo da história da pedagogia em contexto brasileiro tem como marco os meados do século XX, quando conseguiu uma autonomia no campo da produção de conhecimentos científicos, após um percurso complexo, pregresso e amplo. Entretanto, mesmo com o sentido independente como ciência, como campo de estudos científico, a pauta da instrução pública não recebeu as devidas atenção e financiamento, fazendo com que perdurasse a visão de formação de professores presente 
no excerto anterior: como um curso destinado a moças que aspiravam um casamento e melhora do quadro social e/ou reconhecimento da sociedade, relegando a etapa formativa da escola normal como um acessório, um apêndice na ordem das coisas.

O trecho a seguir é uma fala do personagem João da Mata, padrinho de Maria do Carmo, sobre o contexto público da instrução cearense, que pode ser generalizada às demais regiões do Brasil daquele período, quando se retoma os apontamentos básicos da literatura especializada sobre a instrução daquele período.

O diabo é que no Ceará não havia colégios sérios. A instrução publica estava reduzida a meia dúzia de conventilhos: uma calamidade pior que a seca. $\mathrm{O}$ menino ou menina saia da escola sabendo menos que dantes e mais instruído em hábitos vergonhosos. As melhores famílias sacudiam as filhas na Imaculada Conceição como único recurso para não vê-las completamente ignorantes e pervertidas. (CAMINHA, 2001, p. 21-22).

O tom duro de constatação de João da Mata do cenário educacional, é coerente com a postura do personagem que é avesso à proposta de escolarização ligada a ordens religiosas, como vê-se a seguir. Segundo Caminha (2001, p. 11), o personagem "noutros tempos fora mestre-escola no sertão da província, donde mudara-se para capital por conveniências particulares". Nesse sentido, mestre-escola era sinônimo de professor de primeiras letras, da escola primária. O autor continua afirmando que João da Mata era "então simplesmente o professor Gadelha, o terror dos estudantes de gramática e que [...] estava cansado de ensinar meninos". Para além disso, quando se pensa na trajetória histórica da formação de professores, Saviani (2012) compreende que a educação só se tornou pauta mais concisa do Estado, no século XIX, em razão dos interesses políticos e identitários para a formação da nação.

Durante todo o período colonial, a educação estava ligada à atividade religiosa, não figurando como uma preocupação para a Coroa Portuguesa. Desse modo, pode-se imaginar uma linha de continuidade da presença religiosa no campo educacional, pensando na fragilidade das ações imperiais em prol da instrução. Outro ponto que se aventa, retratado na seção anterior, é que durante o século XIX, embora presente no projeto da formação do Estado e da nação, a obrigatoriedade da instrução pública passa a ser responsabilidade das províncias, indicando a desresponsabilização do governo central para a sistematização das questões do ensino. Esse dado, pode suscitar a refletir a prioridade e a questão orçamentária das províncias para as demandas de instrução (IGLESIAS, 1958). 
$\mathrm{Na}$ passagem que segue, observa-se outra fala do narrador acerca dos pensamentos de João da Mata sobre os assuntos educacionais.

Uma coisa assim fazia até vergonha a ele que detestava tudo quanto cheirasse a sacristia. Porque João da Mata dizia-se pensador livre; não acreditava em santos, e maldizia os padres. Jesus, na sua opinião, era uma espécie de mito, uma como legenda mística sem utilidade prática. Isso de colégios internos à guisa de conventos não se acomodava com o seu temperamento. Também fora professor, olé! e sabia muito bem o que isso era - "um coito de patifarias". Queria a educação como nos colégios da Europa, segundo vira em certo pedagogista, onde as meninas desenvolvem-se física e moralmente como a rapaziada de calças, com uma rapidez admirável, tornando-se por fim excelentes mães de família, perfeitas donas de casa, sem a intervenção inquisitorial da Irmã de Caridade. Não compreendia (tacanhez de espírito embora) como pudesse instruir-se na prática indispensável da vida social uma criatura educada a toques de sineta, no silêncio e na sensaboria de uma casa conventual entre paredes sombrias, com quadros alegóricos das almas do purgatório e das penas do inferno; com o mais lamentável desprezo de todas as prescrições higiênicas, sem ar nem luz, rezando noite e dia - ora pro nobis, ora pro nobis [...] (CAMINHA, 2001, p. 23)

Como no trecho anterior, o personagem reitera seu entendimento contrário aos dogmas religiosos, bem como uma postura avessa à emancipação feminina, no sentido de que a formação das moças deveria prepará-las para o casamento, para o bom trato do marido e para a maternidade. Apesar de em passagens como esta: "uma menina inteligente como Maria devia educar-se no Rio de Janeiro ou num colégio particular, mas um colégio onde ela pudesse aprender o "traquejo social'” (CAMINHA, 2001, p. 24) indicar uma valoração positiva para com a afilhada, bem como o endosso a crítica à instrução pública cearense.

Em acréscimo a essa noção, partindo dos apontamentos de Saviani (2012) e das críticas e desejos de João da Mata, existiu durante o Império a não preocupação com os conhecimentos pedagógicos para os professores, cabendo em sua formação o estudo de cadeiras simples de leitura, de escrita e de cálculo, bem como da prática do Método Mútuo ou Lancaster, retratados na seção anterior, segundo o qual os alunos considerados mais aptos nas matérias, explicavam os conteúdos aos que tinham mais dificuldade. Embora a letargia e as políticas pouco profícuas do período Império, se vislumbrou naquele momento um modelo de Estado e de instrução pública. Já no final do período imperial e início da república, vão se desenhando outras configurações para a escola normal, em razão dos interesses políticos e do anseio pela ideia de modernização nos moldes de produção capitalista. 
As próprias normalistas, Lídia e Maria do Carmo, como a passagem a seguir ilustra também tinham críticas a Escola Normal, principalmente a primeira estudante, que em tom ácido pensa sobre o papel da mulher perante a sociedade e o casamento:

[Maria do Carmo] -E tu, como passas a nova vida?

[Lídia] -Perfeitamente. Desejava antes morar na cidade, mas o Loureiro é muito impertinente, diz que prefere isto -paciência. (...) É verdade, precisas vir passar uns dias comigo, estás muito magra; o ar aqui é melhor que na cidade. Tens ido à Escola?

- A Escola qual!

Passei oito dias em casa, como uma freira, sem ir a parte alguma. Creio que não irei mais àquilo (grifo do autor)

-Eu, no teu caso, faria o mesmo. Agora então, que estou casada, olha... Fez um gesto com as mãos.

-... bananas, não estou para suportar desaforos d'aquela canalha. Porque tudo aquilo é uma canalha, menina. Fazes muito bem não pondo os pés naquela feira de reputações. As raparigas ali aprendem a ser falsas e imorais. Conheço muito o tal Sr. Berredo, o tal Sr. Padre Lima e mais os outros todos. O próprio diretor... eu cá sei... (CAMINHA, 2001, p. 146)

O código moral para as mulheres dos últimos anos do século XIX colocava a "mulher de família" no pedestal da pureza, longe dos maus hábitos das mulheres do mundo. O código que orientava o comportamento feminino passava longe do conhecimento acadêmico e dos espaços escolares, próprios dos homens e hostis para as mulheres (NOVAES, 2015). A mulher, bela, recata e do lar, não deveria se dedicar ao conhecimento. Em uma digressão, essa ideia, longe de estar perdida no tempo, ressurge das cinzas em pleno século XXI.

Percebe-se, também, a estrutura da Escola Normal, onde Maria do Carmo estudava, no excerto abaixo:

[...] contavam-se na sala de aula pouco mais de umas dez alunas, quase todas de livro aberto sobre as carteiras, silenciosas agora, à espera do professor. Maria ocupava um dos bancos da primeira fila. Ao entrar o Berredo, houve um arrastar de pés, todas simularam levantar-se, e o ilustre preceptor sentou-se, na forma do louvável costume, passeando o olhar na sala, vagarosamente, como bonomia paternal - tal como um pastor de ovelhas a velar o casto rebanho. A sala era bastante larga para comportar outras tantas discípulas, com janelas para a rua e para os terrenos devolutos, muito ventilada. Era ali que funcionavam as aulas de ciências físicas e naturais, em horas diferentes das de geografia. Não se via um só mapa, uma só carta geográfica nas paredes, onde punham sombras escuras de peles de animais selvagens colocadas por cima de vidraças que guardavam, intactos, aparelhos de química e física, redomas de vidro bojudas e reluzentes, velhas máquinas pneumáticas nunca servidas, pilhas elétricas de Bunsen, incompletas, sem amálgamas de zinco, os condutores pendentes num abandono glacial; coleções de minerais, numerados, em caixinhas, no fundo da sala, em prateleiras volantes... Nenhum indício, porém, de esfera terrestre [...] (CAMINHA, 2001, p. 73) 
Identificamos também a formalidade nas relações, a austeridade do prédio. Contudo, nota-se na descrição o distanciamento entre o conhecimento e a apropriação dele pelas normalistas. Objetos intactos, máquinas nunca servidas, nos levando a crer que a formação não seria aprofundada o quanto deveria.

Outro trecho, que trata do retorno da personagem para a Escola Normal, depois da gravidez e morte do bebê, também é indicioso para pensar a estrutura da instituição e seus currículos:

[...] meses depois, quando Maria do Carmo apresentou-se na Escola Normal para concluir o curso interrompido, estava nédia e desenvolta, muito corada, com uma estranha chama de felicidade no olhar. A sua presença foi como uma ressureição - "A Maria do Carmo hein? Nem parecia a mesma!" - Houve um alarido entre as normalistas: abraços, beijos, cochichos...Até o edifício tinha-se pintado de novo como para recebê-la. O programa era outro, mais extenso, mais amplo, dividido metodicamente em educação física, educação intelectual, educação e pelos moldes de H. Spencer e Pestalozzi; o horário das aulas tinha sido alterado, havia uma escola anexa de aplicação, estava tudo mudado! A esse tempo um grande acontecimento preocupava toda a cidade. Lia-se na seção telegráfica da Província as primeiras notícias sobre a proclamação da república brasileira. [...] E Maria do Carmo, agora noiva do alferes Coutinho, da polícia, via diante de um futuro largo, imensamente luminoso, como um grande mar tranquilo e dormente. (CAMINHA, 2001, p. 217)

A partir dos excertos percebe-se a mudança curricular tratada nesta e na seção anterior, sobre a formação para os professores do primário. Entretanto, o próprio narrador oferece indícios para pensar se o processo formativo de fato ocorria, a partir de uma noção mais prática dos conhecimentos e referenciando os conteúdos pedagógicos. O trecho nos leva a crer no cumprimento parcial das obrigações de oferecimento das disciplinas e dos materiais, bem como o seu uso pelos estudantes. Essa marca da apropriação das políticas públicas educacionais e da cultura escolar são presentes até na atualidade, marcando diferentes arranjos, interesses e práticas.

Destarte, pelo apresentado, vislumbra-se um horizonte que permite pensar de forma fortuita a aproximação da literatura para o debate com a história da educação, as políticas e legislações educacionais e as instituições escolares. A exemplo de outras fontes, objetos e aportes, deve-se considerar suas especificidades, bem como a relação crítica entre o pesquisador e a obra.

Outro ponto que se evidencia como relevante é o entendimento contextual do autor, da sua inserção em determinada escola literária e a narrativa em si que a obra apresenta. Portanto, subsidiados na fortuna crítica da literatura especializada e em um 
recorte temporal que cobriu parte pregressa e coeva do objeto analisado, pudemos empreender algumas interlocuções acerca da formação de professores e das instituições, partindo de alguns excertos da obra enfocada.

\section{Considerações finais}

Apesar das particularidades, o uso da literatura enquanto fonte, objeto ou aporte para o historiador demanda rigor metodológico e análise crítica, a exemplo do trabalho com outras fontes, não evidenciando o seu caráter monumental, mas sim, situando e organizando os sentidos, os contextos e os sujeitos. A literatura é expressão material e artística clivada de representações e de imaginários de uma época, de determinados produtor e leitor, de dimensões espacial e temporal, repletos de indícios, de sinais e abertas para a ressignificação ao longo do tempo, por seus novos interlocutores.

O texto trouxe uma visada panorâmica acerca de pesquisas produzidas nos programas de pós-graduação acerca da obra literária, evidenciando a relevância da proposição das investigações e apontando a contribuição do presente texto com o paralelo realizado com a escola normal. Em seguida, o artigo pontuou algumas ponderações teórico-metodológicas das relações entre História e Literatura, principalmente, à luz das perspectivas culturais na produção historiográfica. As escolas normais também ambientaram uma seção, que se debruçou a refletir sobre os contextos, os currículos e as políticas que envolviam a instituição. Ao fim, o texto também apresenta um arrazoado sobre a vida do autor e sobre a obra enfocada, debatendo a partir de excertos da obra, questões próprias da escola normal e da sociedade imperial.

Nesse sentido, embora as distinções de método e de público imbricados no ofício do historiador e do literato, acredita-se no encontro dos dois campos, tanto pelos usos em investigações quanto pela reflexão acerca da escrita e da produção do conhecimento em história. A análise do romance A Normalista, de Adolfo Caminha, permite refletir sobre a sociedade e suas organizações, em específico sobre a instituição da escola normal e as interlocuções entre os contextos locais e globais, saltando outras possíveis questões para estudos futuros. Em uma perspectiva ampliada em termos da consideração das trajetórias históricas da educação, notou-se movimentos de (des)continuidade com relação a estrutura, a oferta e as demandas políticas imbricadas com a educação. 


\section{Referências}

ABUD, Katia Maria; SILVA, André Chaves de Melo; ALVES, Ronaldo Cardoso. Ensino de História. São Paulo: Cengage Learning, 2011.

ARAÚJO, Helena de Lima Marinho Rodrigues. A tradicional Escola Normal cearense chega ao bairro de Fátima: formação das primeiras professoras primárias (1958 1960). Doutorado em EDUCAÇÃ̃O Instituição de Ensino: UNIVERSIDADE FEDERAL DO CEARÁ, Fortaleza. 307 p. 2014.

BATISTA, Eliana Evangelista. A Normalista como interseção: escola, literatura, imprensa e estratégias políticas no estado novo (Alagoinhas / 1937-1945). Dissertação (Mestrado em História Regional e Local). Universidade do Estado da Bahia, Salvador. 159 p. 2012.

BORGES, Valdeci Rezende. História e Literatura: Algumas Considerações. Goiás: Revista de Teoria da História, Ano 1, n. 3, junho/ 2010.

BRASIL. Decreto $n$. 7.247, de 19 de abril de 1879. Reforma o ensino primário e secundário no Município da Corte e o superior em todo o Império. Coleção das leis do Império do Brasil, Rio de Janeiro, v. 1, parte 2, p. 196-216, 1880.

BRASIL. Decreto n. 8.025, de 16 de março de 1881. Manda executar o novo Regulamento para a Escola Normal do Município da Corte. Coleção das leis do Império do Brasil, Rio de Janeiro, v. 1, parte 2, p. 189, 1881.

BRASIL. Decreto n. 10.060, de 13 de outubro de 1888. Dá novo Regulamento à Escola Normal. Coleção das leis do Império do Brasil, Rio de Janeiro, v. 2, parte 2, p. 343, 1888 .

BRASIL. Decreto $n$. 346, de 19 de abril de 1890. Cria a Secretaria de Estado dos Negócios da Instrução Pública, Correios e Telégrafos. Decretos do Governo Provisório da República dos Estados Unidos do Brasil, Rio de Janeiro, v. 1, quarto fascículo, p. 641-642, 1890.

BRASIL. Decreto n. 982, de 8 de novembro de 1890. Altera o Regulamento da Escola Normal da Capital Federal. Coleção das leis da República dos Estados Unidos do Brasil, Rio de Janeiro, décimo primeiro fascículo, p. 3513, 1890.

BRASIL. Lei $n$. 85, de 20 de setembro de 1892. Estabelece a organização municipal do Distrito Federal. Coleção das leis da República dos Estados Unidos do Brasil, Rio de Janeiro, parte 1, p. 84-96, 1893.

BURKE, Peter. A história dos acontecimentos e o renascimento da narrativa. In: BURKE, Peter (org.) A escrita da História: novas perspectivas. São Paulo: Unesp, 1992.

CAMINHA, Adolfo. A Normalista. Fonte digital: www.bn.br, 2001. Disponível em: http://www.ebooksbrasil.org/adobeebook/normalista.pdf . Acessado em dezembro de 2020. 
CÂNDIDO, Antônio; CASTELlO, Aderaldo. Presença da literatura brasileira. 5. ed. São Paulo: Difusão Europeia do livro, 1974.

CHALHOUB, Sidney. Cidade Febril: cortiços e epidemias na corte imperial. São Paulo: Companhia das Letras, 2001.

CHARTIER, Roger. A ordem dos livros: Leitores, autores e bibliotecas na Europa entre os séculos XIV e XVIII. Trad. Mary Del Priore. Brasília: Editora da UnB, 1994

A história ou a leitura do tempo. Belo Horizonte: Autêntica, 2009.

COUTINHO, Afrânio. A literatura no Brasil. Parte II / Estilos de época. $7^{\circ}$ ver. ed. Atual. - São Paulo: Global, 2004.

DARNTON, Robert. História da leitura. In: BURKE, Peter. A escrita da História: Novas Perspectivas. SP: Ed. Da UNESP, 1992, p. 199 - 232.

FARIA FILHO, Luciano Mendes. Instrução elementar no século XIX. In: LOPES, Eliane Marta Teixeira; FARIA FILHO, Luciano Mendes e VEIGA, Cynthia Greive. 500 anos de educação no Brasil. Belo Horizonte: Autêntica, 2000, p. 497-518.

IGLESIAS, Francisco. Política econômica do governo provincial mineiro (1835-1889). Rio de Janeiro: MEC; INL, 1958.

KULESZA, Wojciech Andrzej. A institucionalização da Escola Normal no Brasil (1870-1910). Revista Brasileira de Estudos Pedagógicos, Brasília: Inep. v. 79, n. 193, p. 63-71, set./dez. 1998.

MEN, Liliana; NEVES, Fátima Maria. O método pedagógico de Lancaster e a cultura escolar. In: CONGRESSO DE LEITURA NO BRASIL, 16, 2007, Unicamp, Campinas. Anais...Disponível em:〈http://www.alb.com.br/anais16/sem07pdf/sm07ss12_06.pdf>. Acesso em: 10 set. 2010.

MORAIS, Nagila Maia de. Entre o mutualismo e o sindicalismo: a resistência solidária dos trabalhadores portuários de Fortaleza (1912-1933). Tese (Doutorado em História). Universidade Federal de Pernambuco, Recife. 289 p. 2017.

NASCIMENTO, Silvia Helena. Personagens Negras: Tigres, Gajeiros e Domésticos na obra de Adolfo Caminha nos fins do século XIX. Dissertação (Mestrado em História). Pontifícia Universidade Católica de São Paulo, São Paulo. 165 p. 2000.

NOVAES, Elizabete David. Entre o público e o privado: o papel da mulher nos movimentos sociais e a conquista de direitos no decorrer da história. História e Cultura, Franca, v. 4, n. 3, p. 50-66, dez. 2015. Disponível em: https://ojs.franca.unesp.br/index.php/historiaecultura/article/view/1691. Acesso em: 07 maio 2021.

PESAVENTO, Sandra Jatahy. História \& História Cultural. Belo Horizonte: Autêntica, 2004. 
PESAVENTO, Sandra Jatahy. História \& literatura: uma velha-nova história, Nuevo Mundo, Mundos Nuevos, Debates, 2006. Disponível em:

http://nuevomundo.revues.org/index1560.html. Acessado em dezembro de 2020.

RIBEIRO, Luis Filipe. Geometrias do Imaginário. Santiago de Compostela: Edicións Laiovento, 2000.

SANTOS, Zeloí Aparecida Martins dos, História e Literatura: uma relação possível. Revista Científica, Curitiba, ano II, v.2, jan-dez/2007. Disponível em:

http://www.fap.pr.gov.br/arquivos/File/RevistaCientifica2/zeloidossantos.pdf. Acessado em dezembro de 2020.

SAVIANI, Dermeval. A pedagogia no Brasil: história e teoria. $2^{\mathrm{a}}$ ed. Campinas: Autores Associados, 2012.

SEVCENKO, Nicolau. Literatura como missão: tensões sociais e criação cultural na Primeira República. São Paulo: Brasiliense, 2003.

SILVA, Ronaldo Antônio Pereira da. Do mestre-escola à normalista: gênese da profissão docente em Sergipe (1870-1911). Dissertação (Mestrado em Educação). Pontifícia Universidade Católica de Minas Gerais, Belo Horizonte. 96 p. 2007.

SOUSA, Jane Bezerra de. Ser e fazer-se professora no Piauí no século XX: a história de vida de Nevinha Santos. Tese (Doutorado em Educação). Universidade Federal de Uberlândia, Uberlândia. 236 p. 2009.

SOUZA, Rosa Fátima de. Templos de civilização: a implantação da escola primária graduada no estado de São Paulo (1890-1910). São Paulo: Ed. Unesp, 1998.

VICENTE, Magda de Abreu. A Escola Normal Regional Imaculada Conceição em Pelotas/RS: a atuação da igreja católica e dos poderes públicos (1955-1971). Tese (Doutorado em Educação). Universidade Federal de Pelotas, Pelotas. 347 p. 2018.

Artigo recebido em 07 de maio de 2021. Aprovado em 26 de junho de 2021. 